\section{Anxiolytic-like and sedative effects of Hydrocotyle umbellata extract in mice}

\author{
Fábio F. Rocha, ${ }^{* 1}$ Cláudio S. Almeida, ${ }^{1}$ Rafael T. dos Santos, ${ }^{1}$ \\ Suely A. Santana, ${ }^{2}$ Elson A. Costa, ${ }^{3}$ José R. de Paula, ${ }^{4}$ Frederico \\ A. Vanderlinde ${ }^{1}$
}

\author{
${ }^{1}$ Departamento de Ciências Fisiológicas, Instituto de Biologia, Universidade Federal \\ Rural do Rio de Janeiro, Brazil, \\ ${ }^{2}$ Unidade Universitária de Ciências Exatas e Tecnológicas, Universidade Estadual de \\ Goiás, Brazil, \\ ${ }^{3}$ Departamento de Ciências Fisiológicas, Universidade Federal de Goiás, Campus \\ Samambaia, Brazil, \\ ${ }^{4}$ Anexo da Faculdade de Farmácia, Universidade Federal de Goiás, Brazil.
}

Revista Brasileira de Farmacognosia Brazilian Journal of Pharmacognosy 21(1): 115-120, Jan./Feb. 2011

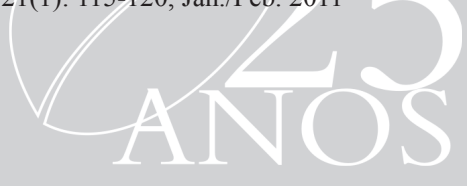

\begin{abstract}
The plant Hydrocotyle umbellata L., Araliaceae (water pennywort), is widely used in Brazilian folk medicine to reduce anxiety. This work investigates the anxiolytic-like effects of the ethanol extract from $H$. umbellata subterraneous parts as well as the extract's other putative central nervous system effects that could justify its common use. Oral dosing of the extract ( 0.3 and 1 $\mathrm{g} / \mathrm{kg}$ ) clearly showed an anxiolytic-like profile in the elevated plus maze test where it increased the percentage of entries into and the time spent in the open arms of the maze. In the marble-burying test, the extract induced anxiolyticlike effects only at a dose of $1 \mathrm{~g} / \mathrm{kg}$, which also causes mild sedative properties in other models. The sedated state was characterized by a slight reduction in spontaneous exploratory activity during the open field test and a potentiating of pentobarbital-induced hypnosis. No signs of motor impairment were detected in the rota rod or chimney tests. The extract did not show antidepressant properties in mice as assessed by the forced swimming test. These results support the use of $H$. umbellata in Brazilian folk medicine as an anxiolytic and contribute to the scientific knowledge of this possible phytotherapeutic resource.
\end{abstract}

Article

Received 26 Mar 2010

Accepted 24 Jun 2010

Available online 25 Feb 2011

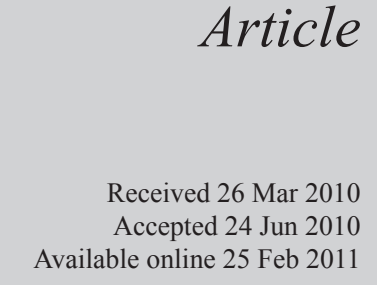

Keywords: anxiolytic elevated plus maze Hydrocotyle umbellata Araliaceae marble burying test mice

ISSN 0102-695X doi: 10.1590/S0102-695X2011005000018

\section{Introduction}

Anxiety disorders are common psychopathologies with lifetime prevalence rates ranging from 13.6 to $28.8 \%$ in Western countries and affect approximately twice as many women as men. They have high co-morbidity with other psychiatric disorders like major depression and phobias (Michael et al., 2007). Benzodiazepines have long been used to treat anxiety, but their prominent side effects, including sedation, muscle-relaxation, ethanol potentiation, anterograde amnesia, and pharmacological dependence, still represent a barrier to long-term treatment with these drugs (Gorman, 2003).

In accordance with the World Health Organization's strategy to ensure the appropriate, safe, and effective use of traditional medicines (Zhang, 2002), and to discover alternative, more specific, and perhaps lower cost therapies, investigations into natural anxiolytic drugs have been conducted.

Hydrocotyle umbellata L. is a water-loving perennial herb from the Araliaceae family that is widely distributed in the Americas. The species is native to Brazil and is commonly known as "acariçoba". It has been used in folk medicine for different purposes including the reduction of anxiety. The central nervous system effects of the genus Hydrocotyle have been exhaustively studied using Hydrocotyle asiatica L. (Centella asiatica (L.) Urb.). Centella was shown to have anxiolytic effects and to improve learning and memory capacity, which may be related to an increase in hippocampal dendritic arborization (Wijeweera et al., 2006; Mohandas Rao et al., 2006). Despite the popular use of $H$. umbellata, its pharmacological properties remain unclear. An additional point of interest related to this plant is the fact that it has been used as an adulterant in Centella preparations (Fischer et al., 1994). Considering these circumstances, the aims of this work were to study the anxiolytic-like effects of $H$. umbellata and to contribute to the scientific knowledge of this potential phytotherapeutic resource to ameliorate anxiety symptoms. 


\section{Material and Methods}

\section{Botanical material and extraction}

The subterranean parts of Hydrocotyle umbellata L., Araliaceae, were collected in the Herbal Medicine Garden of the Pharmacy Faculty of the Federal University of Goiás in March 2000, and the samples were authenticated by Prof. Heleno Dias Ferreira, Department of General Biology/ICB/UFG. Voucher specimens were deposited in the herbarium of the Department of General Biology/ICB/UFG under the number 22394. The dried and milled vegetal material was macerated in ethanol $\left(96^{\circ} \mathrm{GL}\right)$ for three days. After that, the extract was filtered and concentrated to dryness under reduced pressure (below $40{ }^{\circ} \mathrm{C}$ ). The residual vegetal material was submitted twice more to the same process to produce an ethanol extract (EEH) in $4 \%$ yield.

\section{Animals}

Adult male Swiss mice weighing 25-30 g were used in all experiments. Animals were maintained on a $12 \mathrm{~h}$ light-dark cycle (lights on at 7:00 a.m.) and at a constant room temperature $\left(23 \pm 2{ }^{\circ} \mathrm{C}\right)$ with free access to food and water except during the experiments. All experiments were carried out in accordance with international standards of animal welfare, and the experimental protocols were approved by the local Animal Care and Use Committee (004/2006/CEPEB/ UFRRJ).

\section{Drugs}

Diazepam (Diazepan $^{\circledR}, \quad$ Cristalia, Brazil), Sodium pentobarbital (Sigma Chemical Co., USA), and Fluoxetine hydrochloride (Ratiopharm/Mepha, Brazil) were used in the present study. EEH was freshly suspended in $1 \%$ Tween- 80 and tap water immediately before its oral administration $(0.1,0.3$ and $1 \mathrm{~g} / \mathrm{kg}$ ), which always occurred $60 \mathrm{~min}$ before the tests. Other drugs were dissolved in saline solution $(0.9 \%)$ except for fluoxetine, which was dissolved in tap water for oral administration. Control animals received a Tween80 solution $(1 \%)$ in tap water as vehicle $(10 \mathrm{~mL} / \mathrm{kg}$, p.o.).

\section{Elevated plus maze}

This test, which was used to evaluate the anxiolytic effects of EEH, is based on the model proposed by Lister (1987). The tests were carried out under a red light $(15 \mathrm{~W})$. The mouse behavior was filmed for 5 min using an infrared video camera.
After treatment with vehicle, or diazepam $(1 \mathrm{mg} /$ $\mathrm{kg}$, i.p.), each mouse was placed on the central platform facing an enclosed arm. The parameters evaluated included the number of open and enclosed arm entries, the time spent in the open and enclosed arms, the time spent on the central platform, as well as ethologically derived activities, such as rearing, stretched attend postures (SAP), head dipping (HD), and defecation as an emotionally related parameter (Rodgers \& Dalvi, 1997).

\section{Marble-burying test}

This test was carried out in an apparatus consisting of a Plexiglas cage $(42 \times 34 \times 15 \mathrm{~cm})$ in which the floor had been covered with a $2 \mathrm{~cm}$ deep layer of sawdust and 25 glass marbles had been distributed throughout the cage. After treatment with vehicle, EEH or diazepam $(1 \mathrm{mg} / \mathrm{kg}$, i.p. $)$, the mice were individually placed in the cage for $30 \mathrm{~min}$. The mouse was then removed and the burying response was quantified by counting the number of marbles that were more than two-thirds covered with sawdust. To detect any motor impairment that could influence the results of the marble-burying test, the mice were next submitted to a rota rod test where they were placed on a rotating rod $(2.5 \mathrm{~cm}$ in diameter divided into six equal compartments rotating at $12 \mathrm{rpm}$ ) for $1 \mathrm{~min}$. The time spent (in s) on the rotating rod was recorded as the maximum of three trials, which involved returning the mouse to the bar after falling from the apparatus (Dunham \& Myia, 1957).

\section{Barbiturate-induced hypnosis}

One hour after the treatment with vehicle or EEH, each animal was injected with sodium pentobarbital $(50 \mathrm{mg} / \mathrm{kg}$, i.p.). The latency to induce sleep (loss of the righting reflex) and the duration of hypnosis (the time required to recover the righting reflex) were recorded for each animal (Carlini et al., 1986).

\section{Open-field test}

Open-field activity was measured in a Plexiglas cage (height: $15 \mathrm{~cm}$; length: $30 \mathrm{~cm}$; width: $30 \mathrm{~cm}$ ) with a black floor marked with white lines denoting $10 \mathrm{~cm} 2$ areas. After treatment with vehicle, EEH or diazepam $(5 \mathrm{mg} / \mathrm{kg}, i . p$.), each mouse was placed in the center of the arena, and its ambulation, immobility time, rearing, grooming, and defecation were recorded for $5 \mathrm{~min}$. The number of grid lines crossed by both hind feet in a 5 min period was recorded as a metric of ambulation (De Lima, 2002). 


\section{Chimney test}

Immediately after the open field test, the animals were submitted to the chimney test to assess possible motor impairment. In this test, the animals had to climb backwards up a plastic tube $(25 \mathrm{~cm}$ length, 3 $\mathrm{cm}$ inner diameter). The time required to complete the climb was recorded with a maximum of $60 \mathrm{~s}$ (1961).

\section{Forced swimming test}

After treatment with vehicle, EEH or fluoxetine $(30 \mathrm{mg} / \mathrm{kg}$, p.o.), mice were individually forced to swim in a transparent Plexiglas cylinder $(20 \mathrm{~cm}$ high and $10 \mathrm{~cm}$ in diameter) filled with water to a depth of $15 \mathrm{~cm}$ at $21-24{ }^{\circ} \mathrm{C}$. The total duration of immobility was measured during the last $4 \mathrm{~min}$ of a single $6 \mathrm{~min}$ test session. Mice were considered immobile when they made no further attempts to escape and only made movements necessary to keep their heads above water (Porsolt et al. 1977).

\section{Statistical analysis}

The results are reported as the mean standard error of the mean (SEM) and were analyzed statistically using a one-way ANOVA procedure followed by Dunnett's post hoc test. Values of $p$ less than 0.05 $(p<0.05)$ were considered to be significant.

\section{Results and Discussion}

This study evaluated the anxiolytic-like effect of the ethanol extract from the subterraneous parts of Hydrocotyle umbellata L., a plant used in Brazilian folk medicine to reduce anxiety. To assess its effects we used two animal models of anxiety, the elevated plus maze and the marble-burying test. The elevated plus maze test showed that EEH clearly acts as an anxiolytic in mice. As depicted in Figure 1, oral treatment with 0.3 and $1 \mathrm{~g} /$ $\mathrm{kg}$ of the extract significantly increased the percentage of entries into the maze's open arms and additionally the percentage of time spent in these arms increased with the higher dose of the extract. A concomitant decrease in the time spent in the enclosed arms was also observed (Table 1). These parameters are highly correlated to the animal's anxiety state, and anxiolytic drugs are known to induce the more exploratory behavior in maze's open arms (Cruz et al., 1994; Rodgers \& Dalvi, 1997). The ethological parameters observed in the plus maze test are summarized in Table 1. These parameters have been introduced into the plus maze methodology to increase its sensitivity to anxiolytic drugs with mechanisms of action differing from that of the benzodiazepines (Rodgers \& Dalvi, 1997). With this in mind, the reduction in the percentage of protected head dips after treatment with EEH $(0.3$ and $1 \mathrm{~g} / \mathrm{kg})$ adds further evidence of the extract's anxiolytic-like effect. Also, no change in the mice's overall locomotion was observed, since the number of entries into the enclosed arms was unchanged, and this parameter is highly correlated to locomotor activity (Rodgers et al., 1997). These results were similar to those obtained with an anxiolytic dose of diazepam $(1 \mathrm{mg} / \mathrm{kg}$, i.p. $)$, the benzodiazepine used as a positive control in our study.

As shown in Table 1, oral treatment with $1 \mathrm{~g} /$ $\mathrm{kg}$ of EEH reduced the number of marbles buried in a 30 min session of the marble-burying test $(p<0.05)$. This test is a widely applied model of anxiolytic behavior and is sensitive to both benzodiazepines and non-benzodiazepine drugs, such as selective serotonin reuptake inhibitors (SSRI) and tryciclic antidepressants (TCA) (Borsini et al., 2002). The observation of this effect supports the anxiolytic hypothesis for EEH. To rule out the possibility of motor impairment that could influence the test, the animals were submitted to the rota rod test immediately after the end of the session. In the rota rod tests, no motor impairment was detected (data not shown). Another point to consider is that the dose required to produce an anxiolytic-like effect in the marble-burying test was higher than that required in the elevated plus maze. The difference in the minimum effective doses might be explained in terms of the different kinds of anxiety elicited by these models (Borsini et al., 2002). Otherwise, the effective dose in the marble burying test $(1 \mathrm{~g} / \mathrm{kg})$ is the same that produce mild sedative effects in the open field test as described below. Considering this, the reduction of buried marbles in the test could also be attributed to the sedative properties of the extract, although any motor impairment was observed with this dose when the animals were submitted to motor coordinator evaluation tests.

In our study, the highest dose of EEH ( $1 \mathrm{~g} /$ $\mathrm{kg})$ significantly increased $(p<0.05)$ the duration of the hypnosis induced by pentobarbital $(73.8 \pm 10 \mathrm{~min}$ for the EEH-treated group versus $34.3 \pm 5.5 \mathrm{~min}$ for the vehicletreated group), which suggests EEH has a central nervous system depressant activity, although influences in barbiturate metabolism were not discarded. This finding is compatible with the anxiolytic-like effect described in this study, since the effects of pentobarbital on the CNS involve the activation of the inhibitory GABAergic system and can be potentiated by anxiolytic drugs, such as benzodiazepines (Steinbach \& Akk, 2001). The duration of hypnosis was not affected by lower doses of EEH $(0.1$ and $0.3 \mathrm{~g} / \mathrm{kg}$ caused hypnosis for $52.0 \pm 6.2$ and $54.6 \pm 7.0 \mathrm{~min}$, respectively). Also, the time required to induce sleep was not significantly altered by any of the EEH doses (doses of 0.1, 0.3, and $1 \mathrm{~g} / \mathrm{kg}$ resulted in sleep 
after $168.8 \pm 8.0,159.7 \pm 5.4$, and $154.6 \pm 5.8 \mathrm{~s}$, respectively, versus $173.0 \pm 11.1 \mathrm{~s}$ for the vehicle-treated animals).

The highest dose of EEH $(1 \mathrm{~g} / \mathrm{kg})$ reduced the mice's exploratory activity in the open field test, reflecting a slight decrease in ambulation and an increase in their immobility time (Table 2). This effect could result from a mild sedative property of the extract, since the same dose did not induce the impairment of motor coordination in the chimney test (Table 1) or in the rota rod test. This result contrasts those obtained when a sedative dose of diazepam $(5 \mathrm{mg} / \mathrm{kg})$ was used as positive control. With diazepam, a great increase in the immobility time and a decrease in vertical exploration (rearing) were observed in the mice as well as an impairment of motor coordination as evaluated by the chimney test (Table 2). The possibility that higher doses of EEH, which were not tested, could produce stronger sedative effects cannot be ruled out.

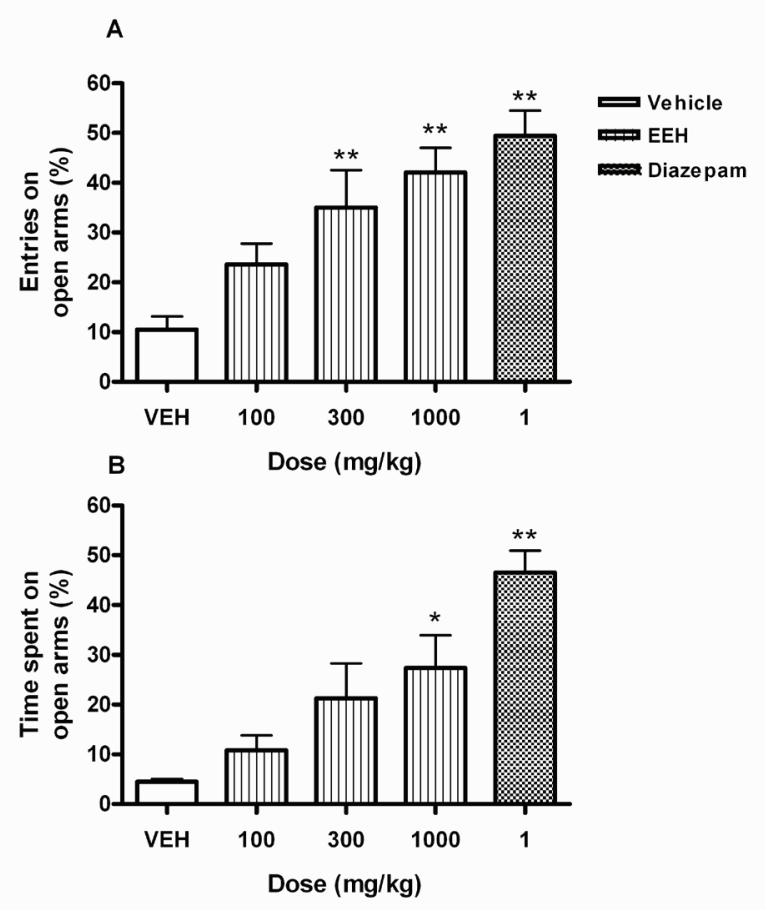

Figure 1. Behavioral performance of mice recorded over a 5 min session in the elevated plus maze $1 \mathrm{~h}$ after the oral injection of vehicle and ethanol extract from Hydrocotyle umbellata L. $(\mathrm{EEH})$, or the intraperitoneal injection of diazepam. (A) Percentage of entries into the open arms and (B) percentage of time spent in the open arms. Each bar represents the mean \pm SEM for eight animals. ${ }^{*} p<0.05$; ${ }^{* *} p<0.01$; One-way ANOVA followed by Dunnett's test.

To study the profile of EEH's central nervous system activity, we also tested its effects in the forced swimming test of depression. With the doses tested, EEH did not present an antidepressant activity as demonstrated in Table 3. The forced swimming test is widely used in the screening of potential antidepressant drugs and has a high predictive validity (Cryan et al., 2005). Since EEH is not effective in this model, the anxiolytic-like effect observed in the elevated plus maze and in the marbleburying test is likely not due to EEH's antidepressant properties.

Preliminary phytochemical analysis indicates the presence of steroids, triterpenes, essential oils, flavonoids, and saponins in EEH, which is in accord with the results previously described by Adams et al. (1989), Fischer et al. (1994), and Martins et al. (2008). When considering the most studied plant of the genus, Hydrocotyle asiatica L., Wijeera et al. (2006) attributed the pharmacological actions of $H$. asiatica to the triterpene rich fractions and described the anxiolytic-like effect of the triterpene asiaticoside in rats, while Chen et al. (2006) showed the anxiolytic-like effects of this compound in mice. The antidepressant-like effect of asiaticoside was also described (Liang et al., 2008). Although our phytochemical prospecting indicates the presence of triterpenes, Fisher et al. (1994) when studying the variety bonariensis Lam of $H$. umbellata did not find the same compounds that where present in the triterpene fraction of $H$. asiatica, which included asiaticoside, madecasic acid, and asiatic acid. Considering this inconsistency, the identification of the triterpenes present in $H$. umbellata should be undertaken, and their putative anxiolytic-like properties must be assessed.

Adams et al. (1989) have described the presence of flavonoids in $H$. umbellata extracts and isolated quercetin-3-O-galactoside (hyperoside) from this species. Several studies have attributed the extract's anxiolytic properties to flavonoids because some of these compounds have the ability to bind the benzodiazepine site in the GABAA receptor (Marder \& Paladini, 2002; Griebel et al., 1999). Because of its pharmacological profile, quercetin3-O-galactoside's cytoprotective properties have been investigated and its potential neuroprotective activity has been suggested (Piao et al., 2008; Liu et al., 2005). By studying hyperoside isolated from $H$. perforatum, Grundmann et al. (2006) detected a partial reduction in open field induced hyperthermia, which suggests that the compound may contribute to the anxiolytic-like effect of this plant, although it is not the main cause. Extensive studies to assess hyperoside's anxiolytic effect have not yet been conducted, and the contribution of this flavonoid to the anxiolytic-like effect of $H$. umbellata cannot be excluded. The evaluation of the anxiolytic-like effects of other flavonoids present in this plant must also be addressed. Bioguided purification is underway to identify the active components and the mechanisms that underlies the plant's anxiolytic-like effect. 
Table 1. Effects of the ethanol extract of Hydrocotyle umbellata L. (EEH) on mice in the elevated plus maze test and the marbleburying test.

\begin{tabular}{|c|c|c|c|c|c|}
\hline & \multicolumn{5}{|c|}{ Treatment } \\
\hline & \multirow{3}{*}{ Vehicle } & \multicolumn{2}{|c|}{ EEH (p.o.) } & \multicolumn{2}{|c|}{$\mathrm{DZP}(i . p)}$. \\
\hline & & $0.1 \mathrm{~g} / \mathrm{kg}$ & $0.3 \mathrm{~g} / \mathrm{kg}$ & $1 \mathrm{~g} / \mathrm{kg}$ & $1 \mathrm{mg} / \mathrm{kg}$ \\
\hline \multicolumn{5}{|c|}{ Elevated plus maze } & \\
\hline Enclosed arm time (s) & $231.0 \pm 6.6$ & $185.6 \pm 11.6$ & $178.2 \pm 10.5^{*}$ & $167.0 \pm 20.0 * *$ & $127.9 \pm 11.8 * *$ \\
\hline Enclosed arm entries & $9.6 \pm 0.6$ & $8.9 \pm 0.9$ & $8.1 \pm 1.1$ & $7.2 \pm 0.9$ & $9.1 \pm 1.2$ \\
\hline Central time (s) & $58.1 \pm 6.0$ & $90.4 \pm 14.0$ & $74.1 \pm 10.6$ & $71.4 \pm 14.4$ & $61.0 \pm 11.8$ \\
\hline Stretch attend postures & $16.5 \pm 0.9$ & $14.4 \pm 2.6$ & $10.5 \pm 1.4$ & $10.1 \pm 2.0$ & $8.5 \pm 1.6^{*}$ \\
\hline Total head dips & $6.2 \pm 0.9$ & $6.9 \pm 1.2$ & $13.8 \pm 2.2 *$ & $6.6 \pm 1.4$ & $16.6 \pm 3.3 * *$ \\
\hline Protected head dips (\%) & $78.0 \pm 8.4$ & $75.8 \pm 8.5$ & $42.1 \pm 6.2 *$ & $44.3 \pm 13.6 *$ & $23.9 \pm 6.2 * *$ \\
\hline \multirow[t]{2}{*}{ Rearing (number) } & $20.1 \pm 1.8$ & $15.1 \pm 3.4$ & $14.0 \pm 3.1$ & $11.8 \pm 2.4$ & $11.1 \pm 3.2$ \\
\hline & & \multicolumn{2}{|c|}{ Marble-burying test } & & \\
\hline Marbles buried & & $18.6 \pm 2.3$ & $18.6 \pm 2.6$ & $12.1 \pm 1.8^{*}$ & $8.4 \pm 3.2 * *$ \\
\hline
\end{tabular}

Values are given as the mean \pm SEM; ${ }^{*} p<0.05$ and ${ }^{* *} p<0.01$ relative to the control group; One-way ANOVA followed by Dunnett's test; DZP: Diazepam (positive control); Elevated plus maze, $\mathrm{n}=8$; Marble-burying test, $\mathrm{n}=7$.

Table 2. Effects of the ethanol extract of Hydrocotyle umbellata L. (EEH) on mice in the open field test and the chimney test.

\begin{tabular}{|c|c|c|}
\hline & & Vehicle \\
\hline \multicolumn{2}{|c|}{ Ambulation } & $86.3 \pm 5.1$ \\
\hline \multicolumn{2}{|c|}{ Immobility time (s) } & $10.6 \pm 3.9$ \\
\hline \multicolumn{2}{|c|}{ Rearing (number) } & $37.2 \pm 4.0$ \\
\hline \multicolumn{2}{|c|}{ Grooming (s) } & $12.1 \pm 2.2$ \\
\hline \multicolumn{2}{|c|}{ Defecation (number) } & $1.4 \pm 0.5$ \\
\hline \multicolumn{2}{|c|}{ Time spent to leave the chimney } & $7.0 \pm 1.1$ \\
\hline \multicolumn{2}{|c|}{ Number of animals } & 10 \\
\hline \multicolumn{3}{|c|}{$\begin{array}{l}\text { Values are given as the mean } \pm \mathrm{SEM} ;{ }^{*} p<0.05 \text { and } * * p<0.01 \text { relative } \\
\text { Diazepam }\end{array}$} \\
\hline \multicolumn{3}{|c|}{$\begin{array}{l}\text { Table 3. Effect of the ethanol extract of Hydro } \\
\text { L. (EEH) on mice in the forced swimming test. }\end{array}$} \\
\hline Treatment & Dose (p.o.) & Immobility time (s) \\
\hline Vehicle & - & $116.3 \pm 13.4$ \\
\hline \multirow[t]{3}{*}{$\mathrm{EEH}$} & $0.1 \mathrm{~g} / \mathrm{kg}$ & $101.6 \pm 14.3$ \\
\hline & $0.3 \mathrm{~g} / \mathrm{kg}$ & $121 \pm 21.6$ \\
\hline & $1 \mathrm{~g} / \mathrm{kg}$ & $115.6 \pm 12.6$ \\
\hline Fluoxetine & $30 \mathrm{mg} / \mathrm{kg}$ & $45.1 \pm 13.1 *$ \\
\hline
\end{tabular}

Data are expressed as mean $\pm \mathrm{SEM} ;{ }^{*} p<0.05$ relative to the control group; One-way ANOVA followed by Dunnett's test, $\mathrm{n}=7-8$.

\section{Acknowledgements}

The authors thank the Brazilian National Research Council (CNPq), CAPES, UFRRJ, and FUNAPE/UFG for financial support.

\section{References}

Adams AA, Norris JA, Mabry TJ 1989. A flavonoid from Hydrocotyle umbellata L. (Umbelliferae, Hydrocotyllae). Rev Latinoamer Quim 20: 67-68.

Boissier JR, Dremont C, Robins R., Pagny J 1961. Tentative de pharmacologie previsionelle dans de domain des neuroleptique: actions sedative centralle et adrenolytique de la $N($ dimethoxy-3,4 phenethyl) N(chloro-2 phenyl) piperazine. Arch Int Pharmacodyn Ther 133: 29-32.

Borsini F, Podhorna J, Marazziti D 2002. Do animal models of anxiety predict anxiolytic-like effects of antidepressants? Psychopharmacology 163: 121-141.

Broekkamp CL, Rijk HW, Joly-Gelouin D, Lloyd KL 1986. Major tranquilizers can be distinguished from minor tranquilizers on the basis of effects on marble burying and swim-induced grooming in mice. Eur J Pharmacol 126: 223-229. 
Carlini EA, Contar JDP, Silva-Filho AR, da Silveira-Filho NG, Frochtengarten ML, Bueno OF 1986. Pharmacology of lemongrass (Cymbopogon citratus Stapf). Effects of teas prepared from the leaves on laboratory animals. $J$ Ethnopharmacol 17: 37-64.

Chen SW, Wang WJ, Li WJ, Wang R, Li YL, Yan Ni Huang YN, Liang X 2006. Anxiolytic-like effect of asiaticoside in mice. Pharmacol Biochem Behav 85: 339-344.

Cruz AP, Frei F, Graeff FG 1994. Ethopharmacological analysis of rat behavior on the elevated plus-maze. Pharmacol Biochem Behav 49: 171-176.

Cryan JF, Valentino RJ, Lucki I 2005. Assessing substrates underlying the behavioral effects of antidepressants using the modified rat forced swimming test. Neurosci Biobehav Rev 29: 547-569.

De Lima TCM 2002. Evaluacion de la actividad y el comportamiento motor. In: Lapa AJ, Souccar C, LimaLandman MTR, Monteiro de Lima TC, eds., Métodos de Evaluación de la Actividad Farmacológica de Plantas Medicinale. Editograf, CYTED/CNPq: Florianópolis, Brasil, p. 76-78.

Dunham NW, Miya TS 1957. A note on a simple apparatus for detecting neurological deficit in rat and mice. $\mathrm{J} \mathrm{Am}$ Pharm Assoc 46: 208-209.

Fischer DCH, Kato ETM, Oliveira F 1994. Estudo farmacognóstico de Hydrocotyle bonariensis Lam. Adulterante de Centella asiatica (L.) Urban. Lecta Rev Farm Biol 12: 71-102.

Gorman JM 2003. Treating generalized anxiety disorder. $J$ Clin Psychiatry 64 (Suppl 2): 24-29.

Griebel G, Perrault G, Tan S, Schoemaker H, Sanger DJ 1999. Pharmacological studies on synthetic flavonoids: comparison with diazepam. Neuropharmacology 38: 965-977.

Grundmann O, Kelber O, Butterweck V 2006. Effects of St. John's wort extract and single constituents on stressinduced hyperthermia in mice. Planta Med 72: 13661371.

Liang X, Huang YN, Chen SW, Wang WJ, Xu N, Cui S, Liu XH, Zhang H, Liu YN, Liu S, Yang M, Dong Y 2008. Antidepressant-like effect of asiaticoside in mice. Pharmacol Biochem Behav 89: 444-449.

Lister RG 1987. The use of a plus-maze to measure anxiety in the mouse. Psychopharmacology 92: 180-185.

Liu Z, Tao X, Zhang C, Lu Y, Wei D 2005. Protective effects of hyperoside (quercetin-3-o-galactoside) to PC12 cells against cytotoxicity induced by hydrogen peroxide and tert-butyl hydroperoxide. Biomed Pharmacother 59: 481-490.

Marder M, Paladini AC 2002. GABA (A)-receptor ligands of flavonoid structure. Curr Top Med Chem 2: 853-867.

Martins MBG, Marconi AP, Cavalheiro AJ, Rodrigues SD 2008. Caracterização Anatômica e Química da Folha e do Sistema Radicular de Hydrocotyle umbellata (Apiaceae). Rev Bras Farmacogn 18: 402-414.

Michael T, Zetsche U, Margraf J 2007. Epidemiology of anxiety disorders. Psychiatry 6: 136-142.

Mohandas Rao KG, Muddanna Rao S, Gurumadhva Rao S 2006. Centella asiatica (L.) leaf extract treatment during the growth spurt period enhances hippocampal CA3 neuronal dendritic arborization in rats. Evid
Based Complement Alternat Med 3: 349-357.

Piao M J, Kang KA, Zhang R, Ko DO, Wang ZH, You HJ, Kim HS, Kim JS, Kang SS, Hyun JW 2008. Hyperoside prevents oxidative damage induced by hydrogen peroxide in lung fibroblast cells via an antioxidant effect. Biochim Biophys Acta 1780: 1448-1457.

Porsolt RD, Bertin A, Jalfre M 1977. Behavioral despair in mice: a primary screening test for antidepressants. Arch Int Pharmacodyn Ther 229: 327-236.

Rodgers RJ, Dalvi A 1997. Anxiety, defence and the elevated plus-maze. Neurosc Biobehav Rev 21: 801-810.

Rodgers RJ, Cao BJ, Dalvi A, Holmes A 1997. Animal models of anxiety: an ethological perspective. Braz J Med Biol Res 30: 289-304.

Steinbach JH, Akk G 2001. Modulation of GABA(A) receptor channel gating by pentobarbital. J Physiol 537: 715733.

Wijeweera P, Arnason JT, Koszycki D, Merali Z 2006. Evaluation of anxiolytic properties of Gotukola (Centella asiatica) extracts and asiaticoside in rat behavioral models. Phytomedicine 13: 668-676.

Zhang X 2002. WHO Traditional Medicine Strategy 2002-2005. World Health Organization: Geneva. http://whqlibdoc.who.int/hq/2002/WHO_EDM_ TRM_2002.1.pdf, access in march 2010 .

\section{*Correspondence}

Fábio F. Rocha

Departamento de Ciências Fisiológicas, Instituto de Biologia, Universidade Federal Rural do Rio de Janeiro, BR 465, km 07, Seropédica, 23890-000 Rio de Janeiro-RJ, Brazil

farocha@ufrrj.br

Tel: +552126823222

Fax: +552126821763 